\title{
Strategic Human Resource Management: The Calibrated Catalysts for Indian IT-SMEs Performance Optimization
}

\author{
K. L. Santhosh Kumar ${ }^{1 *}$ and M. Lokanadha Reddy ${ }^{2}$ \\ 'Research Scholar, School of Commerce, REVA University, Bengaluru, India \\ ${ }^{2}$ Research Supervisor, REVA University, Bengaluru, India
}

\begin{abstract}
In last few years, the emergence of globalization and liberalization across the world has enabled globaleconomies to explore and create more business opportunities to meet rising Information Technology (IT) or software related demands. In any economy 'Small and Medium Size (SME's) enterprises', especially IT firms have been playing vital role. Organizations are focussing on exploring more opportunities to achieve competitive gain and success; however, in this journey the role of human resources can't be ignored. To achieve competitive gain firms require introducing more calibrated and optimal resource management strategies to achieve higher productivity, competitive business advantages, etc. In any firm managing human resource optimal acquisition, retention, training and retraining etc., play decisive role for productive outcome. In current competitive scenario where, different IT companies provide healthier and more competitive facilities to it employees, implementing Strategic Human Resource Management (SHRM) becomes an inevitable need. With this motivation, this research paper presents an empirical research with mixed research paradigm to study efficacy of SHRM in Indian listed IT companies. Different stakeholders including HR managers and employees of IT SMEs have been interviewed for their perception towards the need of SHRM to achieve better firm performance. This study has revealed that SHRM can play vital role in employee's retention and quality acquisition where training and retraining can help business houses to retain undisrupted pace of growth. This eventually augments firm performance.
\end{abstract}

Keywords: Information Technology, Indian Listed Companies, Small and Medium Enterprise companies, Strategic Human Resource Management

\section{Introduction}

Human Resources are the asset for any organisation and it is the source of achieving competitive advantage and company performance are influenced by a set of effective HRM practices. Managing HR is very challenging as compared to managing technology or capital and for effective management; organization requires effective HRM system. HRM system should be backed up by sturdy human resource management practices. Human resource management can help the firms to improve organizational behaviour in the areas of staff competency, commitment and flexibility, which in turn lead to improve staff performance. HRM practices gives prolific results like enhancing employee commitment and retention, reduced the employee turnover. The first transformation incorporated the recognition that 'people are an important asset in an organizations' that can be directed scientifically. It involves 'co-ordinating the shape and substance of

*Email: santhoshkumarkl@gmail.com 
the many traditional personnel policies and practices. "The need for this orchestration was based upon the increasing evidence that all these policies and practices substantially affect human behaviour. These needs are reflected in discussions of the major issues and direction of the organization, i.e., the strategy of the firm, the transformation of human resource management came to be known as strategic human resource management" (Schuler \& Jackson, 1999). On the other hand, 'organizations in present trend constantly tussle with revolutionary changes viz., global competition, deregulation, technological and demographic change', they must strive to withstand in the turbulent business environment.

SMEs have been identified as one of the dominating business environment which has played significant role in economic growth and innovation. Non-deniably, SMEs is recognized as a priority sector in almost all the countries. It is evident that, half to two third of businesses all over the world are SMEs. Majority of the SMEs comprise a widely divergent spectrum of establishments, engaged in varied economic activities ranging from micro and rural enterprise to modern industrial units using sophisticated technologies development and exploration. In fact, these SMEs contribution towards the national economies, the importance and emphasis on SMEs has been accentuated in the minds of policy makers and the industry in the recent past. In fact, it is a consequence of the recognition that 'shift from agrarian to industrial' and to post industrial knowledge based societies shall not be through the large industrial houses but through individual and small initiatives by visionaries of the SMEs.

\section{Related Works}

Noe et al., (2003) stated "HRM referred to the policies, practices and systems that influence employees' behavior, attitudes, and performance". According to Rodwell et al., (2009) and Heathfield (2000) "HRM as the organizational function that deals with issues related to human such as hiring, compensation, performance management, organization development, safety, wellness, benefits, employee motivation, communication and administration". 'HRM is the function within an organization that focuses on recruitment, management and providing direction for the people who work in the organization. The available humanities report that the Indian HRM system(s) is somewhat unstructured, and less formal, when compared to Western countries, though the gap is reducing rapidly' (Bjorkman et al., 2007; Budhwar, 2001; Budhwar \& Sparrow, 2002; Budhwar et. al., 2009; Budhwar et. al., 2006). The HRM function in the Indian context is significantly influenced by issues such as "social relations, political connections, caste, religion, economic power, labour legislation, trade unions, and competition from foreign firms" (Budhwar \& Sparrow, 2002; Saini \& Budhwar, 2007). Furthermore, researchers have also examined various aspects of organisational behaviour (Varma et al., 2005) and organizational dynamics and the influence of national culture of Indian HRM (Budhwar et. al., 2009).

Considering market dynamism and exceedingly increasing non-linear patterns of human resource perception and retention related factors such as competitive market, change management as per demands etc. HRM with classical approaches seems confined. The organisations that 'do not adopt a strategic approach are easily recognized by a fragmented and ad-hoc approach' to the development and implementation of human resources activities. In those organizations that do not adopt a strategic approach, existing approaches often act as barriers to the implementation of strategy rather than as "levers to support or facilitate it, they are at risk of reacting to somebody's agenda".Failure to haveastrategic approach to HRM will directly impact on the performance of the organization, however it is measured. Critically, failure to take a strategic approach will have implications for costs, efficiency, productivity and quality. To address such issues, recently SHRM process was proposed. Schuler (1992) proposed the model of strategic HRM which melded various HR activities with strategic needs. These five P's (HR Philosophy, policies, programme, Practices and Process) according to him can be "categorized into strategic on the basis as to whether they are systematically linked to the strategic needs of the business". Rodwell et al., (2009) stated 
that strategic HRM (SHRM) could be achieved through the cultivation of an external orientation to customers' demands and a commitment to employees. Considering the significance of SHRM in present day competitive and dynamic market, a number of researches have been done to assess its efficacy towards a specific kind of industry. It has been found that resources and allied skills, their capabilities and experiences in conjunction with their capability to employ these towards the benefit of an organization can lead and cause significant contribution for organizational productivity and performance. The key SHRM approaches such as, efficient resourcing, resource training and retraining, ability development, fair and cooperative employee relations, retention measures and compensation management are of utmost significance. To achieve it SHRM plays vital role where it enables how optimally the resources could be employed and managed so as to augment overall organizational productivity (Katou, 2006). Dessler (2007) suggested the notion of the configurationally adaptive viewpoint that emphasizes on the approaches to relate different patterns of multiple independent variables, so as to identify ideal organizational HR strategy. HRM is considered as the critical resources where their skills and commitment create competitive advantage across market. Majority of researchers advocate for SHRM practices and recommend it to enable higher performance (Wright et al., 2009). However, the optimal practices and processes and allied theoretical conceptualizations are not much addressed. However, their empirical study revealed that in practice it is not inevitable that stronger fit between HRM practice and strategy.

Observing literatures published during $80 \mathrm{~s}$ and $90 \mathrm{~s}$, it can be found that authors stated to have no relationship between HRM strategy and firm's performance. On contrary the recent literatures from 2002 AD reveal that the emerging competitiveness and globalization has forced business houses from different business and services to consider resources with suitable or even better capacity and productivity that requires SHRM as must. Undeniably, in last few years a number of firms and businesses have came into existence that to grow its business require human resources with optimal quality for which it employs varies strategies or programmes such as training and retraining, appraisal on regular interval, change management and many more. It eventually help firm to retain employees with potential to sustain optimal productivity and quality of products and/or services. On the other hand, researchers (Som, 2006) have identified that there are numerous leading Indian companies like Infosys and Wipro that have adopted innovative SHRM practices to cope up with the expectations and deliveries of the local labour market. The same companies execute varied standard benchmarks for foreign investors, which are less familiar with the conditions for HRM in India. It becomes significant to ensure higher productivity or performance of the firm by incorporating SHRM practices that as a result helps in promoting company to gain market share and/or investment.

\section{Research Methodology}

The study intends to explore and analyse the employee's perception towards the HRM practices of the company. This study intends to assess whether the key SHRM practices like innovative retraining - redeployment practices, index of perceived organizational performance, innovative recruitment practices, "innovative performance appraisal, innovative compensation and reward practices" could help augmenting or improving SME-firm's performance. It can help the company to rectify and enrich the human resource activities to enable in building better employees working relationship and increase the productivity, operational efficiency, and innovation as well as revenue growth.

\section{Objectives of the Study}

- To examine various SHRM policies and practices in Indian SMEs, and

- To assess SHRM and its impact on job satisfaction of employees.

\section{Hypothesis}

$\mathbf{H}_{\mathbf{0 1}}$ : There is no correlation between Strategic HRM (SHRM) implementation and organizational performance, especially IT-SMEs of India. 
$\mathbf{H}_{\mathbf{0 2}}$ : Various paradigms i.e., innovative recruitment practices, training and retraining, performance appraisal practices, and reward and compensation practices enable resource productivity, higher organizational performance and QoS.

$\mathbf{H}_{\mathbf{0 3}}$ : There is no Innovative retraining and redeployment practices have positive relationship with organizational performance productivity and QoS in Indian IT-SMEs.

\section{Data Collection}

Being a mixed research paradigm, in this study consist both the primary and secondary data have been taken into consideration. Since the presented study intends to explore employee's perception towards SHRM practices by the IT-SMEs and its impact on firm's performance, understanding key factors affecting employee's decision process and their expectations can be vital. Understanding employee's potential enrichment and working relationship with SHRM can also be efficient to identify optimal SHRM measure for eventual organizational goals (i.e., higher performance). With this objective, this study primary and secondary data have been considered. A snippet of the data considered is given as follows:

\subsection{Secondary Data Collection}

In this study, Secondary data have been considered, where the secondary data has been collected from sources like literatures, articles, books, magazines, catalogues, journals, news papers etc. Various internet resources have been considered to study the different competency management practices and HRM policies being applied to build better employees working relationship to ensure optimal firm's performance.

\subsection{Primary Data Collection}

Being an empirical study, to perform quantitative assessment research questionnaires has been prepared which has been circulated amongst the respondents. In this study, company's HRs and working employees from IT-SMEs are considered as the respondent. To collect data, semi-structured interviews have been conduct with these respondents. The responses have been collected through personal interviews, which were conducted based on individual meetings. The presented study confines it's Region of Interest (RoI) till IT-SMEs, to generalize the study outcome respondents from different geographical locations and working conditions are considered for interviews. Here, a total of 45 IT-SMEs have been considered for a case study where a total of 750 respondents are interviewed for respective perception towards "SHRM practices and its association with firm's performance". The descriptive questions are closed ended which are prepared in the 5-ponts likert's scale, with Strongly Agree (5), Agree (4), Neutral (3) Disagree (2) and Strongly Disagree (1) responses as the personal perception towards the defined question.

The distribution of the research questionnaires are given in Table 1.

Table 1. Questionnaire distributions

\begin{tabular}{|l|l|}
\hline Type of Question & Total Numbers \\
\hline HRM Philosophy and relationship with Management & 6 \\
\hline Strategic role of HRM Activity & 7 \\
\hline Innovative Retraining - Redeployment Practices & 3 \\
\hline Index of perceived organizational performance & 6 \\
\hline Total & $\mathbf{2 2}$ \\
\hline
\end{tabular}

However, performing outlier detection a total number of 750 respondents were selected for study. Noticeably, considering flexibility in terms of reach ability and the willingness of the respondent's convenient sampling method has been applied. Our applied random convenience sampling method are far the easiest probability sampling technique in terms of conceptualization and application does not necessarily require adequate knowledge of the exact composition of the population, so long as we can reach all the members of the population.

\subsection{Tools for Data Analysis}

Once collecting the responses it has been processed for tabulation and outlier detection which is followed by the data analysis. In this research Social Package for Statistical Study (SPSS) 11.5 computer program is applied for data analysis. The prepared samples were at first processed for the reliability test for which 
Chronbach Alpha is obtained for each question types and clusters (Table 1). Here, the Chronbach Alpha for each category has been found more than 0.5 that signifies relevancies and continuity of the questionnaires and the responses. Once assuring reliability of the responses, the collected data has been processed for statistical assessment in terms of mean, medium, and Pearson correlation etc. the detailed discussion of the statistical parameters used and their respective significances is given in the sub-sequent sections.

\section{Data Analysis}

This section primarily discusses the descriptive characterization of the different research variables and respective significance towards SHRM, its efficacy for firm's performance enhancement. To perform descriptive analysis, responses collected for different questions based on 5-points Likert's scale has been assessed.

\subsection{SHRM Outlook in your Organization}

The HR management philosophy is not only specifying the functioning of human resources. It is mainly involves the guidance style of the management, the current corporate culture and values. It is related to the vision mission of the manager of the organization. The strategic leader generally needs a strategic HR Management approach and creates the environment appropriate for the evolution of the current HR Management (Table 2).

Table 2. HRM Philosophy and liaison with top management

\begin{tabular}{|l|l|l|}
\hline HRM Philosophy \& liaison with Top Management & Mean & SD \\
\hline $\begin{array}{l}\text { Top management develops \& communicates HRM } \\
\text { philosophy to all the staff }\end{array}$ & 4.373 & 0.537 \\
\hline Top management conducts periodic discussions & 4.820 & 0.385 \\
\hline $\begin{array}{l}\text { Top management design development oriented appraisal } \\
\text { system \& its review }\end{array}$ & 4.546 & 0.651 \\
\hline $\begin{array}{l}\text { Shaping HRM plans to suit goals, strategies, } \\
\text { diversification }\end{array}$ & 4.706 & 0.456 \\
\hline $\begin{array}{l}\text { Conducting orientation workshops for different HRM } \\
\text { systems }\end{array}$ & 3.586 & 0.677 \\
\hline $\begin{array}{l}\text { participate in the activity of certified bodies like NHRD, } \\
\text { NIPM etc. }\end{array}$ & 3.433 & 0.727 \\
\hline
\end{tabular}

The development of the HR management philosophy is a long term process. The top management of the organisation has its significant influence on the HR philosophy and its execution. The top management generally compares the organization performance with their direct competitors and based on that defines better strategic solution so as to compete with the competitors and gain benefits. If they find the requirement of performance enhancement factors to compete in the market, they provoke the changes of the corporate culture as well as HR philosophy that intend to augment trade off of resource working culture and organizational performance. This study revealed that the top management is a part of development and execution of the HRM philosophy to the staffs of the organization $(\mathrm{M}=4.440, \mathrm{SD}=0.937)$. However, observing higher SD signify difference in opinions. It is because in last few years majority of the SMEs formed in Bangalore, and Chennai are the subsidiary of different business verticals and operating across globe. In such cases execution of HRM significantly depends on regional office preventative or regional directors. Furthermore, being up-surging market segment SMEs do consider cooperative culture to formulate cumulative acceptable strategy for HR decision. In any organization the periodic reviews and discussion about the strategic planning is more significant. Conduction of periodic reviews of ethics policies can help to verify that business process as well as procedures are fallowed correctly and that no shortcuts are taken. The respondents are strongly agreed that their organization, top management conducts periodic discussions about the employee performance, policies and results of adopted strategies $(\mathrm{M}=4.820, \mathrm{SD}=0.385)$. Performance appraisals are considered as one of the best way of evaluating the employees. Such appraisal consists of purpose, free of favoritisms and custom-designed to fit the specific requirements of an organization. The appraisal system designed by the top management should be uniform in terms of procedures and should be easy to operate. Almost $90 \%$ of the respondents do agree with this construct that the appraisal system designed must be properly documented and should provide procedures for review or appeals $(\mathrm{M}=4.546$, $\mathrm{SD}=0.651$ ). Almost 94\% respondents stated SHRM is the process of shaping HR strategy that focuses on reaching the organizational goals, taking decisions which deals with diversification etc., $(\mathrm{M}=4.706$, 
$\mathrm{SD}=0.456$ ). It has also been observed that to handle the risks and responsibility of management HRs require a proper training and workshops to assess employee's concerns that eventually could help avoiding retention related risks. On the other hand, there are a number of process and practices that could be applied to augment retention and motivating employees. The conduction of orientation workshops on job descriptions and recruitment process, gender equity, policies and procedures, HRM issues, organizational behavior, conduction of external and internal trainings and staff reduction and termination process etc., will generates better HRs. This study revealed that a major fraction of recently formed IT-SMEs in South Indian cities are not conducting orientation workshops, however only partial number of respondents affirmed that their organization conducting orientation workshops for different HRM systems $(\mathrm{M}=3.580, \mathrm{SD}=0.984)$. In this competitive world, to provide the better suggestions and information about the SHRM, many nationalized committees such as National Human resource Department (NHRD), Nationeal Institute of Personnel Management (NIPM) has built. The NHRD network is the national Apex body of professionals, who are engaged in promoting the HRD movement in the country and improving the potential of the human resource professionals to compete globally and their by creating value for the society. On the other hand, NIPM is the Indian body of professional managers, who are involved in the profession of human resource management, Industrial Relations, Labour Welfare, and Training and development in the country. Majority of the respondents affirmed that their organization has not yet participated in the activities of professional bodies like NHRD, NIPM etc., $(\mathrm{M}=3.433, \mathrm{SD}=0.893)$.

\subsection{Strategic Role of HRM Activities}

Main objective of HR management is to contributing organizational success. The HRM activities involve the organizational efforts focusing on productivity, service, and quality. The HRM function deals with the people and issues such as compensation, hiring, performance management and training. Hence the vital in organization are role of HR activities. The strategic role of the HR implies the group of tactical choices connected with the employment relations management, which describes the ability of the organization build the effective relationship with the employees to obtain the superior productivity. HRM practices are categorized on the continuum varies from soft hard HR practices. Organization may adopt elements of soft and hard HR practices in managing their employees. All the strategic HRM activities of the organization intended to take advantages of the possible complementarities among HR practices, polices, processes and programmes. Through the strategic activities organization can be able to optimize their utilization of opportunities. Strategic integration is an inevitable necessity in building the stability between human resource strategy and organizational strategy (Table 3 ).

Table 3. Strategic role of HRM activities

\begin{tabular}{|l|l|l|}
\hline Strategic Role of HRM Activities & Mean & SD \\
\hline $\begin{array}{l}\text { "HRM has played a significant role in the success } \\
\text { of this organization" }\end{array}$ & 4.853 & 0.373 \\
\hline $\begin{array}{l}\text { "HRM Personnel in our organization are } \\
\text { cooperative and respected" }\end{array}$ & 3.813 & 0.972 \\
\hline $\begin{array}{l}\text { "HRM is proactive in this organization anticipates } \\
\text { changes and corporate failures" }\end{array}$ & 3.973 & 0.802 \\
\hline $\begin{array}{l}\text { "HR Managers are coaches rather than } \\
\text { controllers" }\end{array}$ & 4.786 & 0.457 \\
\hline $\begin{array}{l}\text { "HRM is about building employer-employee } \\
\text { working relationship" }\end{array}$ & 4.646 & 0.479 \\
\hline $\begin{array}{l}\text { "HRM Dept. benchmarks with the global } \\
\text { competency practices" }\end{array}$ & 4.353 & 0.636 \\
\hline $\begin{array}{l}\text { "Overall the HRM Policies of this organization } \\
\text { are fair" }\end{array}$ & 3.620 & 1.121 \\
\hline
\end{tabular}

Every organization is intended to be a top performer in the corporate. To be in a top competitor in the market place organization needs some strategies to increase the productivity of the organization. This in terms depends on the effort and skills of the people or employees of the organization. On the other side, the performance of the organization depends on the HR. HRM plays a significant role to maintain good relationship with the employees and their satisfaction, which as a result augments productivity or performance of an employee. This can further incorporated with the organizational competitive advantages, and directly contribute to the organization's success $(\mathrm{M}=4.853, \mathrm{SD}=0.373)$. It is indeed that, HR teams in the organization are pillars of the business process. Since HR's are responsible of hiring right people at right time and providing training 
and managing tasks which in terms increases the business growth. If the HR representative is supportive, good communicator with employees, its management team and everyone who are the part of business operation, then the performance of the organization increases. Moderate number of respondents affirmed that the HRM Personnel in their organization are cooperative and respected $(\mathrm{M}=3.813, \mathrm{SD}=0.972)$. It has been found that in IT-SMEs there is a need of improvement in HR behaviors in terms of critical thinking while taking decisions, lean-thinking and leadership skills to augment day-to-day management. The better HR team in the organization is the strength of the organization. The decisions taken and practices fallowed by the HR executives have its identical influence on the organizational performance. Lacking of managing the human resource of the company leads to corporate failures in many ways. Hence the HR executives should be dynamic in their professional. The analyzing capacity by the HR executive for small changes or issues that harm the organizational performance as well as correcting or modifying that changes within the short period of time may escapes from corporate failures. Very few respondents are affirmed that the HR executives of their organization are proactive in the organization and anticipate changes and avoid corporate failures $(\mathrm{M}=3.973, \mathrm{SD}=0.802)$.

HRs of the company play dual role in the organization they may either act as coachers or controller in the organization. In the controlling task HR's are monitoring the tasks being assigned to the employees, where they may observes the how much work has been done, any progress of the project or any additional requirement of the employee if someone is on leave or need of one more extra employee in the team so that in that work could be completes within the shortest period etc., If everything is going well there is no need to do anything. The controlling functions of HRs include employee's performance appreciation, discipline policies, employees' training and observation. In controlling activity they mainly checks the employees behaviours and performance, where they tries to increase the performance by providing training who are not up to reaching the target, by identifying required skills for job or task and developing a plan to teach the skills to employees. While in coaching, it is nothing but giving their feedback, generally to executives or Managers, about how to reach their individually best in their organizational management role. Being a coach, HR executives try to encourage the employees in every stage by telling their strength and weakness in the working environment. The respondents are strongly agreed that HR managers do perform well in coaching the employees well rather than being a controller in the organization $(\mathrm{M}=4.786, \mathrm{SD}=0.457)$. There are two kinds of HR management process; one is HRM with hard human resource practices, where they focus on strict fallowing of rules and policies. While the other one emphasizes on maintaining friendly relationship with employees. It is because maintaining a good relationship with the employees increases the performance of the firm significantly. Hence it is mandatory for the HR executives to facilitate better working environment and taking employees feedback about what issues they are facing and fulfilling them may leads the employees to perform well. Therefore, almost $93.2 \%$ of the respondents stated that building the better employee working relationship is essential $(\mathrm{M}=4.646, \mathrm{SD}=0.479)$. In any organization performance is excellent when there is an effective management of all the resources. As the HR department which is responsible for maintaining good relationship with employees as well as management team, better planning and implementation of strategies towards increasing the performance of the organization may creates global competitions with the organizations. The $87 \%$ of the respondents agreed that IT-SMEs are adopting SHRM practices which is focusing on creating global competencies $(\mathrm{M}=4.353, \mathrm{SD}=0.636)$. Effective human resource management policies are allied with the strategy among the HR and the organizational goals. Since the achievement of the firm depends up on the manpower of the company, HR policies are the guiding procedures towards achieving organizational goals. A good practices involves providing better working environment, less stress on employees, compensation policies, recruitment and selection policies and making better project teams which involves developer, coder, tester who are having better skill, which makes the 
reaching the target in short period. Approximately $72 \%$ of the respondents agreed and confessed being satisfied with HRM policies of their organization $(M=3.620$, $\mathrm{SD}=1.121)$.

\subsection{SHRM Policies in Organization}

As already discussed SHRM policies can provide optimistic guidelines and recommendation to the companies to manage its resources with optimal practices and resource management activities. It acts as a reference points when employment practices are being developed and when decisions are being made about its resources and respective responsibilities. This study revealed that the SHRM policies could facilitate generalized guidance for the companies to maintain optimal working relationship and expected productivity. Training and retraining employees for change management and goal oriented task are must for a company to maintain higher productivity. Training new-comers as well as existing employee may be biggest task for the organization, particularly in a fast changing business environment. HRD may more cautious about providing training to the employees in their current position as well as developing skills for their future roles and responsibilities. Almost $94 \%$ of the respondents stated that personnel returning from training are encouraged to use what they have been learnt in their training program $(\mathrm{M}=4.720, \mathrm{SD}=0.450)$. The first step in any attempt to enhance the employee's performance is counseling or coaching. Coaching is a part of the everyday communication either between the supervisor and the employee who works in the specific area, or a human resource professional and line organization staff members. Coaching normally involves the converting the working issues into a learning opportunity. Coaching involves helping, guiding, encouraging and creating opportunity to perform and do things differently. Respondents strongly agreed that, coaching by managers helps a lot in increasing skills in this organization $(\mathrm{M}=4.866, \mathrm{SD}=0.341)$. Further respondents affirmed that the opportunity provided by the organization to work in special project team encourages their spirit in guiding the team members $(M=4.666, S D=0.472)$ (Table 4).
Table 4. SHRM policies in organization

\begin{tabular}{|l|l|l|}
\hline SHRM Policies in Organization & Mean & SD \\
\hline $\begin{array}{l}\text { "Personnel returning from training are encouraged to use } \\
\text { what they have been learnt in their training program" }\end{array}$ & 4.720 & 0.450 \\
\hline $\begin{array}{l}\text { "Coaching by Boss/Line Manager helps a lot in increasing } \\
\text { skills in this organization" }\end{array}$ & 4.866 & 0.341 \\
\hline $\begin{array}{l}\text { "Selection to Special Project Teams motivates personnel } \\
\text { in this organization" }\end{array}$ & 4.666 & 0.472 \\
\hline
\end{tabular}

\section{Hypothesis Testing}

Taking into consideration of the proposed research objectives and respective subject matter analysis, in this study certain research hypotheses have been defined. The proposed research hypotheses represent the major factors such as SHRM implementation, innovative recruitment practices, training and retraining, performance appraisal practices, reward and compensation practices, organizational performance productivity, and QoS etc., In order to examine these key constructs and motivational factors, in this study questionnaires have been prepared. Collecting the responses and processing the retrieved responses from HR executives and employees, in this study hypothesis proposed have been tested or examined using statistical tools such as Microsoft Excel and SPSS analysis performed in terms of mean, standard deviation and correlation.

\section{$\mathrm{H}_{1}$ : There is positive correlation between strategic HRM (SHRM) implementation and organizational performance, especially IT-SMEs of India.}

(Table 5) presents the Pearson correlation analysis for hypothesis-1 verification, where factors such as SHRM implementation in the organization and organizational performance have been examined.

Table 5. Correlation analysis of the SHRM implementation and organizational performance

\begin{tabular}{|l|l|l|l|}
\hline \multicolumn{2}{|l|}{ Correlations } & $\begin{array}{l}\text { SHRM } \\
\text { implementation }\end{array}$ & $\begin{array}{l}\text { Organizational } \\
\text { performance }\end{array}$ \\
\hline \multirow{2}{*}{$\begin{array}{l}\text { SHRM } \\
\text { implementation }\end{array}$} & $\begin{array}{l}\text { Pearson } \\
\text { Correlation }\end{array}$ & 1 & $0.304^{* *}$ \\
\cline { 2 - 4 } & Sig. (2-tailed) & & 0.000 \\
\hline \multirow{2}{*}{$\begin{array}{l}\text { Organizational } \\
\text { performance }\end{array}$} & $\begin{array}{l}\text { Pearson } \\
\text { Correlation }\end{array}$ & $0.304^{* *}$ & 1 \\
\cline { 2 - 4 } & Sig. (2-tailed) & 0.000 & \\
\hline
\end{tabular}

${ }^{* *}$ Correlation is significant at the 0.01 level (2-tailed). 
This hypothesis is tested at the confidence level of $95 \%$ (or at 0.05 confidence level). From the (table 5) it has been observed that correlation co-efficient is 0.304 at the significance level of 0.000 , which is less than the significance level. Hence the null hypothesis is accepted which implies that

There is a positive relation between SHRM
Implementation and organizational performance,
especially Indian listed IT-SMEs

It infers that organizational performance increases when the HR practices are strategically fitting and reliable. In other way it indicates that, SHRM practices can be of paramount significance to enhance organizational performance and practices by encourages employees to work in flexible working environment.

$\mathbf{H}_{2}$ : Various paradigms such as innovative recruitment practices, training and retraining, performance appraisal practices, reward and compensation practices enable resource productivity, higher organizational performance in Indian IT-SMEs.

To evaluate the impacts various paradigms such as innovative recruitment practices, training and retraining, performance appraisal practices, reward and compensation practices towards enhancing resource productivity, higher organizational performance, a factor analysis was performed using Principal Components Analysis technique (Table 6).

Table 6. KMO and Bartlett's Test

\begin{tabular}{|l|l|l|}
\hline \multicolumn{3}{|l|}{ KM0 and Bartlett's Test } \\
\hline 'Kaiser-Meyer-Olkin' Measure of Sampling Adequacy. & $\mathbf{0 . 5 2 0}$ \\
\hline 'Bartlett's Test of Sphericity' & Approx. Chi-Square & 118.938 \\
\hline & Df & 55 \\
\hline & Sig. & 0.000 \\
\hline
\end{tabular}

The 'Kaiser-Meyer-Olkin' Measures the sampling adequacy is 0.520 which is greater than the expected value of 0.5 and hence it is feasible to run factor analysis. The level of significance show the (.000) of the test (Table 7).

Principal component factor analysis is used for the measuring online visual merchandising cues followed by Varimax rotation. All the 11 factor variables in the questionnaire are reduced to 5 common factors. Out of which the first factor contribute to 1.442 percent variance, second factor contributes to 1.426 percent variance, third factor contributes to 1.406 percent variance, forth factor contributes to 1.275 percent variance and the fifth factor contributes to 1.229 percent variance in the total variance.

Table 7. Total Variance of principal component analysis

\begin{tabular}{|c|c|c|c|c|c|c|c|c|c|}
\hline \multirow[t]{2}{*}{ Com-ponent } & \multicolumn{3}{|c|}{ Initial Eigen values } & \multicolumn{3}{|c|}{ Extraction Sums of Squared Loadings } & \multicolumn{3}{|c|}{ Rotation Sums of Squared Loadings } \\
\hline & Total & $\%$ of vari-ance & Cumu-lative \% & Total & $\%$ of vari-ance & Cumu-lative $\%$ & Total & $\%$ of vari-ance & Cumu-lative \% \\
\hline 1. & 1.750 & 15.909 & 15.909 & 1.750 & 15.909 & 15.909 & 1.442 & 13.112 & 13.112 \\
\hline 2. & 1.534 & 13.941 & 29.850 & 1.534 & 13.941 & 29.850 & 1.426 & 12.960 & 26.072 \\
\hline 3. & 1.287 & 11.699 & 41.549 & 1.287 & 11.699 & 41.549 & 1.406 & 12.785 & 38.857 \\
\hline 4. & 1.137 & 10.336 & 51.885 & 1.137 & 10.336 & 51.885 & 1.275 & 11.594 & 50.451 \\
\hline 5. & 1.071 & 9.737 & 61.622 & 1.071 & 9.737 & 61.622 & 1.229 & 11.172 & 61.622 \\
\hline 6. & 0.930 & 8.455 & 70.078 & & & & & & \\
\hline 7. & 0.866 & 7.873 & 77.950 & & & & & & \\
\hline 8. & 0.737 & 6.704 & 84.655 & & & & & & \\
\hline 9. & 0.617 & 5.606 & 90.261 & & & & & & \\
\hline 10. & 0.580 & 5.268 & 95.529 & & & & & & \\
\hline 11. & 0.492 & 4.471 & 100.000 & & & & & & \\
\hline
\end{tabular}


Table 8. Rotated component matrix table

\begin{tabular}{|c|c|c|c|c|c|}
\hline \multicolumn{6}{|l|}{ Rotated Component Matrixa } \\
\hline & \multicolumn{5}{|c|}{ Component } \\
\hline & 1 & 2 & 3 & 4 & 5 \\
\hline $\begin{array}{l}\text { 'Most of the persons with professional training \& qualification are recruited for Supervisory \& } \\
\text { Managerial Levels' }\end{array}$ & & & & & 0.623 \\
\hline 'Information about job vacancies is easily available within the organization' & & 0.835 & & & \\
\hline $\begin{array}{l}\text { 'There is formal induction, orientation and familiarization process designed to help the new managerial } \\
\text { recruits to understand this organization'. }\end{array}$ & & 0.811 & & & \\
\hline $\begin{array}{l}\text { 'Managerial personnel are allowed to appeal or challenge against Appraisal decisions made by } \\
\text { Supervisors'. }\end{array}$ & 0.824 & & & & \\
\hline 'Inter Personal Skills are important in Performance Appraisal'. & 0.796 & & & & \\
\hline 'HR Department has provided all the staff a clear explanation of the policy and its implementation'. & & & 0.813 & & \\
\hline 'Ranking/Grading in Performance Appraisal directly relates to the performance at work.' & & & & 0.635 & \\
\hline ‘Performance Appraisal System has enhanced role clarity in this organization’ & & & 0.811 & & \\
\hline 'There is freedom to work in flexible hours in this organization'. & & & & & 0.751 \\
\hline 'The rewards offered are directly proportionate to the performance and contribution at work'. & & & & 0.708 & \\
\hline ‘This organization provides a clear explanation of remuneration policy and its implementation. & & & & 0.545 & \\
\hline \multicolumn{6}{|l|}{$\begin{array}{l}\text { Extraction Method: 'Principal Component Analysis'. } \\
\text { Rotation Method: 'Varimax with Kaiser' Normalization. } \\
\text { a. Rotation converged in } \mathbf{5} \text { iterations. }\end{array}$} \\
\hline
\end{tabular}

(Table 8) depicts the rotated factor loadings for the eleven variables of innovative recruitment practices, training and retraining, performance appraisal practices, reward and compensation practices in SHRM practices. It shows the maximum value obtained by the rotated component matrix for each factor.

It has been observed that eleven variables are extracted into 5 factors in this study and are explained as follows:

\section{Factor 1: Persons with Professional Training and Qualification}

It explains the professional training and qualification of the person in the position of Managers as well as supervisor. In other words it explains the knowledge and experience of the managers and supervisor in taking decision, strategic planning as well as managing the human resource (15.909). Hence it also explains the responsibility of the mangers such as HR department has provided all the staff a clear explanation of the policy and its implementation (8.455).

\section{Factor 2: Information about Job Vacancies}

This factor explains the source of the information about the job recruitment. The structure of the organization should be in such a manner that the need of employees or additional requirement of employees in each section in the organization needs to be clearly visible as well as determined within the organization (13.941). It also explains the factor such as organization provides a clear explanation of remuneration policy and its implementation during interview process (4.471).

\section{Factor 3: Design of Formal Induction, Orientation and Familiarization Process}

This factor explains the strategy of the organization in maintaining the organizational function to be constant ongoing process even though the new managers have been appointed. Hence this process could help the new mangers to understand the organizational functions and operation (11.699). It also explains the factor such as performance appraisal system has enhanced role clarity in this organization (6.704). 
Factor 4: Capability of Managerial Personnel to Appeal or Challenge Against Appraisal Decisions

This factor explains the ability of managerial person to raise voice against the dissatisfaction on decision made by the supervisor on providing appraising the employees (10.336). This factor also explains the impact of types of appraisal approaches such as ranking/ Grading (7.873) and offering rewards to the employees (5.268) on the performance and contribution at work.

\section{Factor 5: Inter Personal Skills}

This factor explains the inter personnel skill (9.737) and freedom to work in flexible hours in this organization (5.606).

From the factor analysis it has been observed that,

Various paradigms such as innovative recruitment
practices, training and retraining, performance
appraisal practices, reward and compensation
practices enable resource productivity, higher
organizational performance and QoS in Indian
SMEs.

$\boldsymbol{H}_{3}:$ Innovative retraining and redeployment practices have positive relationship with organizational performance in Indian IT-SMEs.

To analyse the inter-relationship between the innovative retraining and redeployment practices and organizational performance, productivity, and QoS, Pearson correlation analysis has been done. The table below explains the correlation analysis of these variables (Table 9).
The correlation analysis of the innovative retraining and redeployment practices has positive impacts on the organizational performance as it depicted the correlation value of 0.259 , which is at the significance level 0.01 . Hence the null hypothesis is accepted. This implies that

Innovative re-training and redeployment practices
have been positive relationship with organisational
performance, productivity, and QoS in Indian
IT-SMEs.

It infers that instead of hiring new employees, providing training to the existing employees and redeploying them in the work enhances the performance of the organization as they already know the objectives or goal of the organization clearly. On the other hand providing the ongoing training to the employees will provide the opportunity for the employees to know about their strength and weakness in the organization, hence they can able to put their high effort in achieving target of the company. Further, it reduces the hiring or recruiting and training cost of the new candidate, as they take some times to adjust to the company.

\section{Conclusion and Recommendation}

In this paper an empirical analysis was done to assess the significance of SHRM and allied functions for better resource management and firm performance augmentation. The presented study was an empirical research accomplished with a mixed research paradigm employing both qualitative as well as quantitative research methods. Two types of respondents, HR managers and employees of IT SMEs were interviewed through semi-structured interviews

Table 9. Correlation analysis of the Innovative retraining and redeployment practices and organizational performance

\begin{tabular}{|l|l|l|l|}
\hline \multicolumn{2}{|l|}{ Correlations } & Innovative retraining and redeployment practices & organizational performance \\
\hline \multirow{2}{*}{ Innovative retraining and redeployment practices } & Pearson Correlation & 1 & $0.259^{* *}$ \\
\cline { 2 - 4 } & & & 0.000 \\
\hline \multirow{2}{*}{ Organizational performance } & Sig. (2-tailed) & & 1 \\
\hline \multirow{2}{*}{${ }^{* \star}$ Correlation is significant at the 0.01 level (2-tailed) } & Pearson Correlation & $0.259^{* *}$ & \\
\cline { 2 - 4 } & Sig. (2-tailed) & 0.000 & \\
\hline
\end{tabular}


using questionnaires and their perception towards SHRM practices was assessed. This research revealed that undeniably SHRM has been playing vital role in SMEs, especially for quality employee hiring, training and retention. The different SHRM process and practices such as Innovative recruitment, Innovative Performance Appraisal, training and retraining etc helps firm to retain quality employee for long time that alleviates the issue of attrition and hence helps in maintaining optimal growth momentum. This as a result helps in gaining better performance. Thus, the overall research or study revealed that SHRM do have vital role in augmenting firm's performance and hence IT firms require adopting optimal and innovative SHRM practices to exploits its efficacy for competitive gain and higher productivity.

\section{Reference}

Bjorkman, I. \& Budhwar, P. (2007), When in Rome, Human resource management and the performance of foreign firms operating in India, Employee Relations. 29(6):595-610. https://doi.org/10.1108/01425450710826104.

Budhwar, P. (2001). Doing business in India, Thunderbird International Business Review. 43(4):549-68. https://doi. org/10.1002/tie.1013.

Budhwar, P.S. \& Mellahi, K. (2006). Managing human resources in the Middle East, London, Routledge. https:// doi.org/10.4324/9780203485828. PMid: 16901001.

Budhwar, P.S. \& Sparrow, P.R. (2002). An integrative framework for understanding cross-national human resource management practices, Human Resource Management Review. 12(3):377-403. https://doi. org/10.1016/S1053-4822(02)00066-9.

Budhwar, P.S., Varma, A., Malhotra, N. \& Mukherjee, A. (2009). Insights into the Indian call centre industry: can internal marketing help tackle high employee turnover? Journal of Services Marketing. 23(5):351-62. https://doi. org/10.1108/08876040910973459.
Budhwar, P.S., Varma, A., Singh, V. \& Dhar, R. (2006). HRM systems of Indian call centres: An exploratory study, The International Journal of Human Resource Management. 17(5):881-97. https://doi. org/10.1080/09585190600640976.

Dessler, G., (2007). Human resource management. New Delhi: Prentice Hall of India Private Limited, 2007.

Katou, A. \& budhwar, (2006). The effect of human resource management systems on organizational performance: Test of a marketing model, International Journal of Human Resource Management. 17(7):1223-53. https:// doi.org/10.1080/09585190600756525.

Noe, R.A., Hollenbeck, J.R., Gerhart, B. \& Wright, P.M. (2003). Human Resource Management, Gaining a Competitive Advantage, McGraw-Hill, Irwin, pp.5-6, p.218, p.330, p.498, p.327, p.519.

Rodwell, J.J. \& Teo, S.T.T. (2009). Approaches to HRM on the Pacific Rim: A Comparison across Ownership Categories in the Australian Hospitality Industry, Research and Practice in Human Resource Management. 8(1):135-51.

Saini, D. \& Budhwar, P. (2007). Human resource management in India, In: R. Schuler \& S. Jackson (eds), Strategic Human Resource Management, Oxford, Blackwell; p. 287-312.

Schuler, R.S. (1992). Strategic human resource management: Linking the people with the strategic needs of the business, Organisational Dynamics. 21(1):18-32. https://doi.org/10.1016/0090-2616(92)90083-Y

Schuler, R.S., \& Jackson, S.E. (1999). Strategic Human Resource Management. Retrieved January 10, 2009

Som, A. (2006). Bracing for MNC competition through innovative HRM practices: The way ahead for Indian firms, Thunderbird International Business Review. 48(2):207-37. https://doi.org/10.1002/tie.20093.

Varma, A., Pichler, S. \& Srinivas, E.S. (2005). The role of interpersonal affect in performance appraisal: evidence from two samples-the US and India, International Journal of Human Resource Management. 16(11):2029-44. https://doi.org/10.1080/09585190500314904.

Wright P.M. \& Barney, J.B. (2009). On becoming a strategic partner: The role of human resources in gaining competitive advantage. 